\title{
Who is staying home and who is not? Demographic, socioeconomic, and geographic differences in time spent outside the home during the COVID-19 outbreak in Japan
}

\author{
Tomoya Hanibuchi $^{\mathrm{a}, *}$, Naoto Yabe ${ }^{\mathrm{b}}$, Tomoki Nakaya ${ }^{\mathrm{a}}$ \\ ${ }^{a}$ Graduate School of Environmental Studies, Tohoku University, Aoba, 468-1, Aramaki, Aoba-ku, Sendai, Miyagi 980-8572, Japan \\ b Department of Geography, Tokyo Metropolitan University, 1-1 Minami-Osawa, Hachioji-shi, Tokyo 192-0397, Japan
}

\section{A R T I C L E I N F O}

\section{Keywords:}

COVID-19

Self-restraint

Going-out behavior

State of emergency

Online survey

Japan

\begin{abstract}
A B S T R A C T
Studies have reported that many people changed their going-out behavior in response to the declaration of a state of emergency related to the coronavirus disease 2019 (COVID-19) in Japan. However, individual attributes of those who tended to stay home have not been examined. Therefore, this study examined the demographic, socioeconomic, and geographic characteristics of people who refrained from going out both before and after a state of emergency was declared. Using data from a nationwide online survey, this study retrospectively investigated the relative amount of time spent outside the home between mid-February and mid-May 2020. Multilevel linear regression analysis was performed to examine the association of time outside with demographic, socioeconomic, and geographic characteristics, and with the anxiety related to going out, in each period. Overall, respondents significantly reduced their time spent outside during the study period, especially after a state of emergency was declared. Those who were young, female, living with two or more people, had lower income, were not working, used public transportation, had chronic disease, and lived in large metropolitan areas were more likely to reduce time outside during a part of the study period. However, no significant differences were observed for occupational class, education, and neighborhood population density. Thus, the results showed a reduction in time outside during the COVID-19 outbreak and the existence of demographic, socioeconomic, and geographic differences in going-out behavior. Socioeconomic disparities and neighborhood differences in going-out behavior, and their influence on health should be continuously monitored.
\end{abstract}

\section{Introduction ${ }^{1}$}

Since the first reported case of coronavirus disease (COVID-19) at the end of 2019, the virus continues to spread globally. As of September 8 , 2020, the number of global cases exceeded 27 million, with more than 890,000 deaths (Johns Hopkins Coronavirus Resource Center, 2020). Non-pharmaceutical interventions such as closure of schools and restrictions on movement (lockdowns) are considered possible policy approaches to reduce the risk of transmission. A study using data from 149 countries and regions showed that physical distancing interventions were associated with reductions in the incidence of COVID-19 (Islam et al.,2020).

In Japan, 71,856 people had been infected and 1363 died as of September 7 (Japanese Ministry of Health, Labour and Welfare, 2020a).
Although the confirmed cases and deaths have been much lower compared to countries like the United States, Brazil, India, Italy, and the UK, people have still made changes in their daily lives, such as avoiding going out, introducing remote working, and engaging in preventive behaviors (Machida et al., 2020; Muto et al., 2020). In response to a rapid increase in the number of confirmed cases, the Japanese government declared a state of emergency, which requested, but did not mandate, that people stay home and avoid inessential outings, in seven prefectures on April 7, 2020 and in the remaining 40 prefectures on April 16. Recent studies have confirmed that people largely changed their behavior following the declarations (Katafuchi et al., 2020; Parady et al., 2020; Yabe et al., 2020; Yamamura and Tsutsui, 2020). For example, using mobility data from mobile phones, Yabe et al. (2020) revealed that, by April 15, human mobility had decreased by $50 \%$,

\footnotetext{
* Corresponding author.

E-mail address: info@hanibuchi.com (T. Hanibuchi).

1 Non-standard abbreviations: DID: densely inhabited district
} 
resulting in a $70 \%$ reduction in social contact in Tokyo.

However, no study has focused on the individual attributes and geographical characteristics of those staying home. Importantly, the stay-at-home request by the Japanese government was based on selfrestraint without legal enforcement or penalties. Thus, it was entirely an individual's choice. Given that physical/social distancing is a practical way to prevent the transmission of COVID-19, determining who was staying home before the declaration of the state of emergency and who stayed home after, is an important way of identifying individuals at higher risk of infection. This is also important because staying home for prolonged periods could lead to deterioration of mental and physical health by increasing mental distress and reducing physical activity (Goethals et al., 2020; Killgore et al., 2020; Tison et al., 2020; Tull et al., 2020).

Further, researchers have been concerned with socioeconomic inequalities related to the risk of COVID-19 transmission (Bambra et al., 2020; Khalatbari-Soltani et al., 2020). For example, studies from the United States, where the highest number of cases and deaths have been observed, have shown that COVID-19 incidence and mortality were associated with poverty level at the zip code (Amram et al., 2020) and county levels (Zhang and Schwartz, 2020). Similar socioeconomic disparities were confirmed in Spain (Baena-Díez et al., 2020). Income inequality (Gini index) was also shown to be related to the number of COVID-19 deaths at the state level in the United States (Oronce et al., 2020). These studies indicate that income, education, and occupation may be key factors in the exposure risk of COVID-19. In addition, population density has been found to be associated with COVID-19 infections and deaths (Amram et al., 2020; Zhang and Schwartz, 2020). Japan has also seen an increased number of cases in metropolitan areas, including Tokyo and Osaka (Japanese Ministry of Health, Labour and Welfare, 2020b). Given that physical/social distancing policies have been implemented to prevent COVID-19 transmission, the association between density and behavioral changes should be explored in more detail. Furthermore, social norms may not be negligible when considering behavioral changes under the declaration of a state of emergency. As Katafuchi et al. (2020) theoretically modeled, those who leave their homes may experience psychological costs arising from the stigma of going out as well as the perceived risk of COVID-19 infection. This psychological factor is worthy of exploration, in addition to socioeconomic and geographic characteristics.

Therefore, using data from a nationwide online survey, this study examined the demographic, socioeconomic, and geographic characteristics, and the anxiety related to going out, of the population who exercised self-restraint regarding leaving their homes before and after the COVID-19-necessitated state of emergency in Japan.

\section{Methods}

\subsection{Data}

A nationwide online survey was conducted for registered panel members of a survey company (Cross Marketing Inc.) from May 19 to 23, 2020. The survey company had access to approximately 4.65 million panel members with diverse characteristics with regard to demographic and socioeconomic status as well as geographic location. Japanese adults aged 20-69 years who owned iphones were recruited from the panel members. The quota sampling design was used: the distributions of age, gender, and geographical region were the same as those of the national population, except for those in their $60 \mathrm{~s}$ because of fewer responses from females in this age group. In total, 1200 respondents answered the online questionnaire. Ethics approval was obtained from the Research Ethics Committee of the Graduate School of Engineering, Tohoku University (20A-3).

\subsection{Dependent variable}

Respondents were asked to retrospectively rate the relative amount of time they spent outside the home by entering a number, with " 10 " corresponding to the normal amount of time spent outside the home before the COVID-19 outbreak. Thus, the number indicated the perceived changes in the time spent outside compared to normal days: for example, " 6 " meant a $40 \%$ reduction, whereas " 12 " referred to a $20 \%$ increase. Although "normal days" were not precisely defined in the question, most respondents would perceive those as occurred in January 2020 or before, as the first confirmed case in Japan was reported in the middle of January. The question was asked for ten time periods: at the beginning, middle, and end of each month from mid-February to midMay 2020. Characteristic events, such as the declaration of the state of emergency, were shown together with the question for each period to reduce recall bias.

\subsection{Independent variables}

The following demographic and socioeconomic variables were used as individual attributes: age (20-29 years, 30-39 years, 40-49 years, 50-59 years, 60-69 years), gender (male, female), household members (one, two or more), education (junior high school/high school, junior (technical) college/vocational school, university/graduate school), household income (less than 3 million yen, 3-7 million yen, 7 million yen or more, unknown), occupation (white-collar job, gray-collar job, blue-collar job, other, not working), use of public transportation (no, yes), and chronic disease (no, yes). Two geographical variables with different spatial scales were also used: large metropolitan areas at the prefectural level and population density at the neighborhood level. The former was a dummy variable identifying six metropolitan prefectures (i.e., Tokyo, Kanagawa, Saitama, Chiba, Osaka, and Hyogo) where many confirmed COVID-19 cases were reported and a state of emergency was declared earlier, and lifted later than other prefectures. The latter was a categorical variable of population density at the neighborhood scale: non-densely inhabited district (non-DID, defined by the 2015 Population Census of Japan), DID with 7015 people $/ \mathrm{km}^{2}$ or fewer, DID with $7016-10,214$ people $/ \mathrm{km}^{2}$, or DID with 10,215 people $/ \mathrm{km}^{2}$ or more. Anxiety concerning the stigma of going out and the infection risk of COVID-19 was assessed using a four-point Likert scale: 1-no anxiety, 2-a little anxious, 3-somewhat anxious, and 4-very anxious.

\subsection{Statistical analysis}

Time spent outside was tabulated by demographic, socioeconomic, and geographic conditions for each period to identify changes in the response distribution according to the independent variables. Multilevel linear regression models were then fitted to the data to estimate regression coefficients and their standard errors, predicting the time spent outside for each period. "Prefecture" was used as a group variable because COVID-19 policies and information have generally been issued and reported at this level. Additional regression models that included the two anxiety variables were also constructed for each period. Of 1200 respondents, those whose educational attainment was unknown $(n=6)$ and postal code was missing $(n=18)$ were excluded from the analysis. Those who input a value of 20 or higher for the question on time spent outside ( $n=15$; two overlapped with those missing postal codes) were also excluded because it was highly unlikely that time outside increased twofold or more. Finally, 1163 samples were used for the analyses.

\section{Results}

The change in the distribution of time spent outside the home during the study period is shown in Fig. 1. In mid-February 2020, more than half of the respondents answered "10," meaning they spent the same time outside the home as they had before the COVID-19 outbreak. In the 


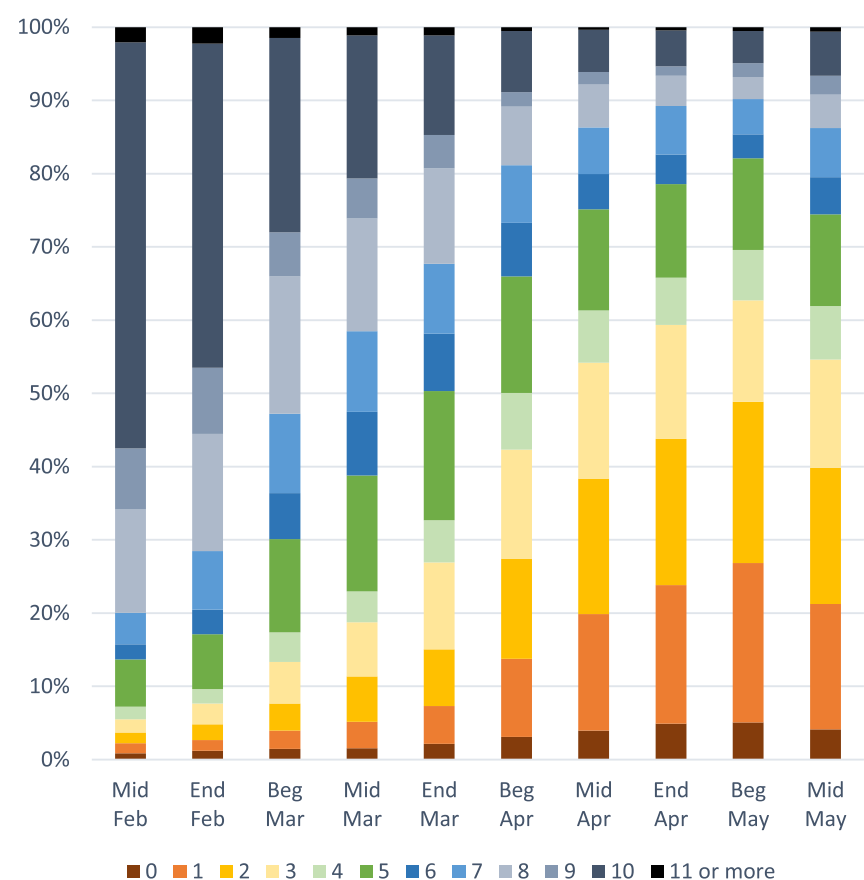

Fig. 1. Distribution of time spent outside between mid-February and mid-May 2020 ("10" corresponded to the normal amount of time spent outside the home before COVID-19), Japan, 2020.

following periods, the proportion of responses of "10" gradually decreased, with responses of "less than 10" increasing. In the beginning and middle of April, the periods during which the state of emergency was declared across prefectures, those who answered "less than 3 " increased rapidly. The trends slightly reversed in the middle of May, the period during which the state of emergency was lifted in the 39 prefectures of non-large metropolitan areas.

Table 1 shows the average evaluation of going-out time according to the respondents' demographic, socioeconomic, and geographic variables for each period. Overall, going-out time declined gradually and was the lowest (3.4) at the beginning of May. Throughout the study period, a reduction in going-out time was clear for all individual attributes. However, significant differences were seen in the all-period average time for age, gender, occupation, and geographic area: respondents aged 20-29 years, those who were female, those not working, and those living in large metropolitan areas showed the largest decrease.

Table 2 shows the results of the regression analyses. Respondents in the 20-29 age group, females, and those not working were consistently less likely to leave their homes during the study period. For example, the coefficients for females were around -0.5 from March to May, meaning that they tended to report going-out time that was $5 \%$ shorter than that for males. Those who lived with two or more household members, had an income of less than 3 million yen, and had chronic diseases also showed reduced time spent outside, but only for the periods before the state of emergency was declared. In contrast, those who used public transportation reduced their time spent outside only after the declaration of the state of emergency. Respondents living in large metropolitan areas tended to stay at home specifically in the period immediately after the state of emergency was declared.

The results of additional analysis that included the two anxiety variables are shown in Table 3. Perceived risk of infection was negatively associated with time spent outside the home from mid-March to mid-May. Perceived stigma was also negatively associated with time spent outside the home, although it was only significant between the beginning of April and the beginning of May.

\section{Discussion}

Although many studies have reported a decline in going out during the state of emergency in Japan (Katafuchi et al., 2020; Parady et al., 2020; Yabe et al., 2020; Yamamura and Tsutsui, 2020), associations of individual attributes and geographical conditions with going-out behavior have not been clarified. Using nationwide online survey data, this study examined the demographic, socioeconomic, and geographic characteristics of people who exercised restraint toward going out before and after the declaration of the COVID-19-necessitated state of emergency in Japan.

Overall, time spent outside gradually declined, with the highest decrease occurring in the beginning of April, when the state of emergency was declared. In the beginning of May, the respondents reported an average decrease of approximately $66 \%$ in time spent outside. This result is largely consistent with previous studies that reported a large reduction in going-out behavior. Yabe et al. (2020) reported that GPSbased human mobility behavior, such as total travel distance per day, decreased by $50 \%$ by April 15 . This suggests that Japanese people in general refrained from going out during the study period even without a mandated lockdown, possibly resulting in the mitigation of the initial outbreak in Japan.

A reduction in the time spent outside was found for all the demographic, socioeconomic, and geographic groups; however, we also found some significant differences according to individual attributes. Regarding demographic variables, younger respondents were more likely to reduce going-out time compared to older respondents. This could be because the current study involved a relative evaluation (i.e., the value of 10 was set for pre-COVID-19 going-out levels), and, because of school and leisure activities, younger people had higher baseline levels of going out, so there was more scope for reduction. In addition, females and those living with two or more household members also showed significantly reduced time spent outside. This may have reflected a higher risk perception of COVID-19 among females and those living with family members to prevent household transmission. School closure from the beginning of March may have been related to this, implying that women bear a greater burden of childcare (Power, 2020).

Regarding socioeconomic characteristics, respondents with lower household income were more likely to reduce their going-out time, but only before the declaration of the state of emergency. Although the reason for this is unclear, those at higher-level positions may have been required to continue commuting to their offices to perform decisionmaking tasks before the introduction of remote-work processes. However, significant differences among occupational classes (i.e., white-, gray-, and blue-collar jobs) were not seen, indicating that using a more detailed occupational classification might be necessary (e.g., a classification based on the possibility of working from home). Instead, those not working, including retirees, homemakers, students, and the unemployed, tended to largely reduce time spent outside the home. This suggests that they may have had less need to commute to the office/ school. Finally, no significant difference was seen for educational attainment.

Thus, although previous studies have been concerned with socioeconomic inequalities in the risk of contracting COVID-19 (Amram et al., 2020; Bambra et al., 2020; Zhang and Schwartz, 2020), effects of socioeconomic differences on self-restraint regarding going-out behavior were not evident, especially after the declaration of the state of emergency in Japan. It is not clear which is healthier, staying home or going outside, as there may be a trade-off between the risk of infection and physical inactivity or mental distress, therefore, further studies are necessary to disentangle the associations between socioeconomic status, going-out behavior, and health outcomes.

The associations of decreased going-out behavior with chronic diseases and the use of public transportation were as expected. As it was repeatedly announced that those with chronic diseases were at higher risk of contracting a severe form of COVID-19, such people may have 
Table 1

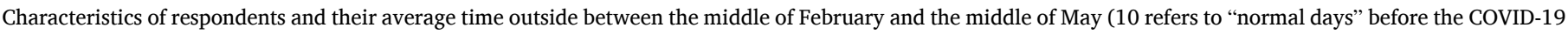
outbreak), Japan, 2020.

\begin{tabular}{|c|c|c|c|c|c|c|c|c|c|c|c|c|c|}
\hline & $\mathrm{n}$ & $\%$ & $\begin{array}{l}\text { Mid } \\
\text { Feb }\end{array}$ & $\begin{array}{l}\text { End } \\
\text { Feb }\end{array}$ & $\begin{array}{l}\text { Beg } \\
\text { Mar }\end{array}$ & $\begin{array}{l}\text { Mid } \\
\text { Mar }\end{array}$ & $\begin{array}{l}\text { End } \\
\text { Mar }\end{array}$ & $\begin{array}{l}\text { Beg } \\
\text { Apr }\end{array}$ & $\begin{array}{l}\text { Mid } \\
\text { Apr }\end{array}$ & $\begin{array}{l}\text { End } \\
\text { Apr }\end{array}$ & $\begin{array}{l}\text { Beg } \\
\text { May }\end{array}$ & $\begin{array}{l}\text { Mid } \\
\text { May }\end{array}$ & Average $^{\text {a) }}$ \\
\hline Total & 1163 & 100.0 & 8.6 & 8.1 & 7.1 & 6.4 & 5.8 & 4.6 & 4.0 & 3.6 & 3.4 & 3.9 & 5.6 \\
\hline Age & & & & & & & & & & & & & $p<0.01$ \\
\hline 20-29 years & 168 & 14.4 & 8.6 & 8.1 & 7.0 & 6.2 & 5.3 & 4.0 & 3.2 & 3.0 & 2.8 & 3.2 & 5.2 \\
\hline $30-39$ years & 231 & 19.9 & 8.7 & 8.2 & 7.1 & 6.3 & 5.6 & 4.3 & 3.7 & 3.5 & 3.4 & 4.0 & 5.5 \\
\hline 40-49 years & 272 & 23.4 & 8.5 & 7.9 & 6.7 & 6.2 & 5.6 & 4.5 & 4.0 & 3.6 & 3.4 & 3.9 & 5.4 \\
\hline 50-59 years & 229 & 19.7 & 8.8 & 8.5 & 7.7 & 7.0 & 6.3 & 5.1 & 4.4 & 3.9 & 3.6 & 4.2 & 5.9 \\
\hline $60-69$ years & 263 & 22.6 & 8.4 & 8.0 & 7.0 & 6.5 & 5.9 & 5.0 & 4.2 & 4.0 & 3.7 & 4.2 & 5.7 \\
\hline Gender & & & & & & & & & & & & & $p<0.001$ \\
\hline Male & 586 & 50.4 & 8.8 & 8.4 & 7.4 & 6.8 & 6.1 & 5.0 & 4.3 & 4.0 & 3.7 & 4.3 & 5.9 \\
\hline Female & 577 & 49.6 & 8.4 & 7.9 & 6.7 & 6.1 & 5.4 & 4.3 & 3.6 & 3.3 & 3.1 & 3.6 & 5.2 \\
\hline Household members & & & & & & & & & & & & & n.s. \\
\hline Two or more & 957 & 82.3 & 8.5 & 8.1 & 7.0 & 6.4 & 5.7 & 4.6 & 3.9 & 3.6 & 3.4 & 3.9 & 5.5 \\
\hline One & 206 & 17.7 & 8.8 & 8.4 & 7.4 & 6.8 & 6.0 & 4.8 & 4.0 & 3.7 & 3.5 & 4.0 & 5.7 \\
\hline Education & & & & & & & & & & & & & n.s. \\
\hline Junior high school/high school & 236 & 20.3 & 8.2 & 7.8 & 6.8 & 6.3 & 5.8 & 4.8 & 4.2 & 3.9 & 3.7 & 4.1 & 5.6 \\
\hline Junior (technical) college/vocational school & 279 & 24.0 & 8.4 & 7.9 & 6.9 & 6.3 & 5.6 & 4.7 & 4.1 & 3.7 & 3.4 & 4.0 & 5.5 \\
\hline University/graduate school & 648 & 55.7 & 8.8 & 8.3 & 7.2 & 6.6 & 5.8 & 4.6 & 3.8 & 3.5 & 3.3 & 3.8 & 5.6 \\
\hline Household income & & & & & & & & & & & & & n.s. \\
\hline Less than 3 million yen & 164 & 14.1 & 8.0 & 7.5 & 6.6 & 6.0 & 5.4 & 4.4 & 3.8 & 3.5 & 3.3 & 3.9 & 5.2 \\
\hline 3-7 million yen & 481 & 41.4 & 8.6 & 8.1 & 7.0 & 6.4 & 5.7 & 4.7 & 4.0 & 3.7 & 3.6 & 4.1 & 5.6 \\
\hline 7 million yen or more & 377 & 32.4 & 8.9 & 8.5 & 7.4 & 6.8 & 6.0 & 4.8 & 4.0 & 3.6 & 3.3 & 3.9 & 5.7 \\
\hline Unknown & 141 & 12.1 & 8.4 & 8.0 & 7.0 & 6.4 & 5.7 & 4.4 & 3.7 & 3.5 & 3.3 & 3.7 & 5.4 \\
\hline Occupation & & & & & & & & & & & & & $p<0.001$ \\
\hline White-collar job & 531 & 45.7 & 8.9 & 8.4 & 7.4 & 6.7 & 6.1 & 4.9 & 4.1 & 3.8 & 3.5 & 4.0 & 5.8 \\
\hline Gray-collar job & 196 & 16.9 & 8.7 & 8.3 & 7.3 & 6.7 & 5.9 & 4.8 & 4.0 & 3.7 & 3.6 & 4.2 & 5.7 \\
\hline Blue-collar job & 94 & 8.1 & 8.4 & 8.1 & 7.2 & 6.7 & 6.2 & 5.2 & 4.6 & 4.4 & 4.0 & 4.7 & 5.9 \\
\hline Other & 91 & 7.8 & 8.9 & 8.4 & 6.9 & 6.4 & 5.8 & 4.2 & 3.7 & 3.3 & 3.2 & 4.1 & 5.5 \\
\hline Not working & 251 & 21.6 & 7.9 & 7.4 & 6.2 & 5.6 & 4.9 & 3.8 & 3.3 & 3.1 & 3.0 & 3.4 & 4.9 \\
\hline Use of public transportation & & & & & & & & & & & & & n.s. \\
\hline No & 680 & 58.5 & 8.4 & 7.9 & 6.9 & 6.3 & 5.6 & 4.7 & 4.2 & 3.9 & 3.7 & 4.2 & 5.6 \\
\hline Yes & 483 & 41.5 & 8.8 & 8.4 & 7.3 & 6.7 & 5.9 & 4.5 & 3.7 & 3.3 & 3.1 & 3.6 & 5.5 \\
\hline Chronic disease & & & & & & & & & & & & & n.s. \\
\hline No & 890 & 76.5 & 8.7 & 8.3 & 7.2 & 6.6 & 5.8 & 4.6 & 3.9 & 3.6 & 3.4 & 3.9 & 5.6 \\
\hline Yes & 273 & 23.5 & 8.1 & 7.6 & 6.6 & 6.1 & 5.6 & 4.7 & 4.1 & 3.7 & 3.4 & 3.9 & 5.4 \\
\hline Large metropolitan areas & & & & & & & & & & & & & $p<0.05$ \\
\hline No & 659 & 56.7 & 8.5 & 8.0 & 7.0 & 6.4 & 5.9 & 4.9 & 4.3 & 3.9 & 3.6 & 4.3 & 5.7 \\
\hline Yes & 504 & 43.3 & 8.6 & 8.3 & 7.1 & 6.4 & 5.6 & 4.3 & 3.5 & 3.3 & 3.1 & 3.5 & 5.4 \\
\hline Neighborhood density & & & & & & & & & & & & & n.s. \\
\hline Lowest (Non-DID) & 278 & 23.9 & 8.6 & 8.1 & 7.1 & 6.3 & 5.7 & 4.8 & 4.2 & 3.9 & 3.6 & 4.1 & 5.7 \\
\hline Low (DID with 7015 people $/ \mathrm{km}^{2}$ or fewer) & 297 & 25.5 & 8.4 & 8.0 & 6.9 & 6.3 & 5.8 & 4.7 & 4.2 & 3.9 & 3.7 & 4.5 & 5.6 \\
\hline High (DID with $7016-10,214$ people $/ \mathrm{km}^{2}$ ) & 296 & 25.5 & 8.6 & 8.1 & 7.1 & 6.7 & 6.1 & 4.9 & 4.1 & 3.7 & 3.3 & 3.8 & 5.6 \\
\hline Highest (DID with 10,215 people $/ \mathrm{km}^{2}$ or more) & 292 & 25.1 & 8.8 & 8.4 & 7.2 & 6.4 & 5.5 & 4.2 & 3.3 & 3.1 & 3.0 & 3.4 & 5.3 \\
\hline
\end{tabular}

a) $\mathrm{p}$ for ANOVA or $t$-test

strongly avoided going outside from mid-February to mid-March. Particularly after the declaration of the state of emergency, people were strongly urged to avoid the three $\mathrm{Cs}$ - closed spaces, crowded places, and close-contact settings-and crowded trains or buses were considered part of these categories. Therefore, people who usually used public transportation may have refrained from doing so, and thus did not go outside often, in late April and May.

Geographical settings were considered relevant to people's decision to stay home during the COVID-19 outbreak. Considering that high population density may be related to an increase in COVID-19 infection rates (Amram et al., 2020; Zhang and Schwartz, 2020), it was hypothesized that residents living in urban settings would stop going out. We considered two variables-large metropolitan areas and neighborhood density-which correspond to large- and small-scale environments, respectively. Although the latter was considered directly related to the three Cs, especially crowded places, no association was found through the multivariate analysis, except for the significant difference between non-DID and low density in mid-May. Instead, those who lived in the six large metropolitan prefectures tended to stay home more than those in the other 41 prefectures in the beginning and middle of April.

This may be because policies and information on COVID-19 have generally been issued and reported at the prefecture level. The reported confirmed cases were extremely high in the six prefectures corresponding to the large metropolitan areas, and the state of emergency was declared earlier in those prefectures. Therefore, residents may have changed their behavior according to the circumstances in the prefectures, rather than those in neighborhoods, right after the state of emergency was declared. A recent study reported that the relationship between density, morbidity, and mortality can vary by spatial scale (Hamidi et al., 2020). The researchers found that county density results in a reduction, rather than an increase, in both COVID-19 infection and death rates after controlling for metropolitan size and other confounding factors. Based on this result, they recommended that urban planners and health professionals continue to advocate for compact development. Although the current study used different outcome variables than Hamidi et al. (2020), the results suggest that researchers should pay more attention to the scale of density, that is, which spatial scale matters for both COVID-19 transmission and the people making behavioral 
Table 2

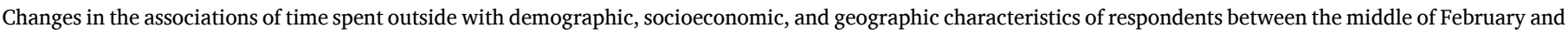
the middle of May estimated by a linear multilevel regression analysis, Japan, 2020.

\begin{tabular}{|c|c|c|c|c|c|c|c|c|c|c|c|c|c|c|c|}
\hline & \multicolumn{3}{|l|}{ Mid-Feb } & \multicolumn{3}{|l|}{ End-Feb } & \multicolumn{3}{|l|}{ Beg-Mar } & \multicolumn{3}{|l|}{ Mid-Mar } & \multicolumn{3}{|l|}{ End-Mar } \\
\hline & B & & S.E. & B & & S.E. & B & & S.E. & $\mathrm{B}$ & & S.E. & B & & S.E. \\
\hline \multicolumn{16}{|l|}{ Age (Ref. 20-29 years) } \\
\hline $30-39$ years & 0.113 & & 0.236 & 0.102 & & 0.252 & -0.038 & & 0.273 & 0.037 & & 0.282 & 0.204 & & 0.290 \\
\hline $40-49$ years & -0.118 & & 0.234 & -0.145 & & 0.250 & -0.325 & & 0.271 & -0.006 & & 0.280 & 0.333 & & 0.288 \\
\hline 50-59 years & 0.310 & & 0.245 & 0.460 & & 0.262 & 0.671 & $*$ & 0.284 & 0.852 & $* *$ & 0.293 & 0.933 & $* *$ & 0.302 \\
\hline $60-69$ years & 0.159 & & 0.236 & 0.307 & & 0.252 & 0.376 & & 0.274 & 0.667 & $*$ & 0.282 & 0.939 & $* *$ & 0.291 \\
\hline \multicolumn{16}{|l|}{ Gender (Ref. Male) } \\
\hline Female & -0.270 & & 0.151 & -0.335 & $*$ & 0.161 & -0.493 & $* *$ & 0.174 & -0.551 & $* *$ & 0.180 & -0.555 & $* *$ & 0.185 \\
\hline \multicolumn{16}{|l|}{$\begin{array}{l}\text { Household members (Ref. Two or } \\
\text { more) }\end{array}$} \\
\hline One & 0.479 & * & 0.197 & 0.446 & * & 0.210 & 0.651 & $* *$ & 0.228 & 0.627 & $* *$ & 0.235 & 0.593 & * & 0.242 \\
\hline \multicolumn{16}{|l|}{$\begin{array}{l}\text { Education (Ref. Junior high school/ } \\
\text { high school) }\end{array}$} \\
\hline $\begin{array}{l}\text { Junior (technical) college/ } \\
\text { vocational school }\end{array}$ & 0.214 & & 0.209 & 0.100 & & 0.224 & 0.177 & & 0.242 & -0.077 & & 0.250 & -0.134 & & 0.257 \\
\hline University/graduate school & 0.317 & & 0.193 & 0.187 & & 0.206 & 0.128 & & 0.223 & -0.112 & & 0.231 & -0.292 & & 0.237 \\
\hline \multicolumn{16}{|l|}{$\begin{array}{l}\text { Household income (Ref. }<3 \text { million } \\
\text { yen) }\end{array}$} \\
\hline 3-7 million yen & 0.613 & $* *$ & 0.220 & 0.607 & * & 0.235 & 0.490 & & 0.255 & 0.366 & & 0.263 & 0.302 & & 0.271 \\
\hline 7 million yen or more & 0.834 & $* *$ & 0.247 & 0.829 & $* *$ & 0.264 & 0.753 & $* *$ & 0.286 & 0.676 & * & 0.295 & 0.500 & & 0.304 \\
\hline Unknown & 0.484 & & 0.274 & 0.580 & $*$ & 0.293 & 0.506 & & 0.317 & 0.587 & & 0.328 & 0.418 & & 0.337 \\
\hline \multicolumn{16}{|l|}{ Occupation (Ref. White-collar job) } \\
\hline Gray-collar job & -0.014 & & 0.198 & 0.109 & & 0.212 & 0.146 & & 0.230 & 0.134 & & 0.237 & -0.051 & & 0.244 \\
\hline Blue-collar job & -0.224 & & 0.273 & -0.145 & & 0.292 & -0.009 & & 0.316 & 0.059 & & 0.327 & 0.070 & & 0.336 \\
\hline Other & 0.253 & & 0.266 & 0.210 & & 0.284 & -0.182 & & 0.308 & -0.122 & & 0.318 & -0.057 & & 0.328 \\
\hline Not working & -0.495 & * & 0.199 & -0.558 & ** & 0.213 & -0.765 & ** & 0.231 & -0.759 & ** & 0.238 & -0.896 & $* * *$ & 0.245 \\
\hline \multicolumn{16}{|l|}{ Use of public transportation (Ref. No) } \\
\hline Yes & 0.169 & & 0.158 & 0.267 & & 0.169 & 0.333 & & 0.183 & 0.289 & & 0.189 & 0.346 & & 0.194 \\
\hline \multicolumn{16}{|l|}{ Chronic disease (Ref. No) } \\
\hline Yes & -0.576 & $* * *$ & 0.165 & -0.665 & $* * *$ & 0.176 & -0.556 & ** & 0.191 & -0.540 & ** & 0.197 & -0.365 & & 0.203 \\
\hline \multicolumn{16}{|l|}{ Large metropolitan areas (Ref. No) } \\
\hline Yes & -0.181 & & 0.197 & -0.085 & & 0.234 & -0.170 & & 0.230 & -0.199 & & 0.253 & -0.300 & & 0.218 \\
\hline \multicolumn{16}{|l|}{$\begin{array}{l}\text { Neighborhood density (Ref. Lowest } \\
\text { (Non-DID)) }\end{array}$} \\
\hline $\begin{array}{l}\text { Low (DID with } 7,015 \text { people } / \mathrm{km}^{2} \\
\text { or fewer) }\end{array}$ & -0.096 & & 0.195 & -0.109 & & 0.209 & -0.169 & & 0.226 & 0.063 & & 0.233 & 0.061 & & 0.239 \\
\hline $\begin{array}{l}\text { High (DID with } 7,016-10,214 \\
\text { people } / \mathrm{km}^{2} \text { ) }\end{array}$ & -0.157 & & 0.209 & -0.242 & & 0.226 & -0.182 & & 0.242 & 0.212 & & 0.252 & 0.247 & & 0.254 \\
\hline $\begin{array}{l}\text { Highest (DID with } 10,215 \text { people/ } \\
\mathrm{km}^{2} \text { or more) }\end{array}$ & 0.001 & & 0.251 & -0.005 & & 0.274 & -0.147 & & 0.291 & 0.019 & & 0.305 & -0.240 & & 0.298 \\
\hline Constant & 8.061 & $* * *$ & 0.357 & 7.654 & $* * *$ & 0.383 & 6.802 & $* * *$ & 0.413 & 6.098 & $* * *$ & 0.428 & 5.531 & $* * *$ & 0.437 \\
\hline Prefecture-level variance & 0.031 & & 0.047 & 0.083 & & 0.065 & 0.045 & & 0.063 & 0.083 & & 0.086 & 0.000 & & 0.000 \\
\hline n (respondents) & 1163 & & & 1163 & & & 1163 & & & 1163 & & & 1163 & & \\
\hline n (prefectures) & 47 & & & 47 & & & 47 & & & 47 & & & 47 & & \\
\hline & Beg-Apr & & & Mid-Apr & & & End-Apr & & & Beg-May & & & Mid-May & & \\
\hline & B & & S.E. & B & & S.E. & B & & S.E. & B & & S.E. & B & & S.E. \\
\hline Age (Ref. $20-29$ years) & & & & & & & & & & & & & & & \\
\hline $30-39$ years & 0.176 & & 0.281 & 0.367 & & 0.272 & 0.433 & & 0.268 & 0.462 & & 0.266 & 0.738 & $* *$ & 0.278 \\
\hline 40-49 years & 0.398 & & 0.280 & 0.646 & $*$ & 0.270 & 0.614 & $*$ & 0.266 & 0.508 & & 0.264 & 0.639 & $*$ & 0.277 \\
\hline 50-59 years & 0.925 & $* *$ & 0.293 & 0.986 & $* * *$ & 0.282 & 0.869 & $* *$ & 0.279 & 0.713 & $*$ & 0.277 & 0.898 & $* *$ & 0.290 \\
\hline $60-69$ years & 1.124 & $* * *$ & 0.282 & 1.079 & $* * *$ & 0.272 & 1.133 & $* * *$ & 0.269 & 1.005 & $* * *$ & 0.267 & 1.157 & $* * *$ & 0.279 \\
\hline Gender (Ref. Male) & & & & & & & & & & & & & & & \\
\hline Female & -0.489 & $* *$ & 0.180 & -0.654 & $* * *$ & 0.174 & -0.614 & $* * *$ & 0.171 & -0.648 & $* * *$ & 0.170 & -0.739 & $* * *$ & 0.178 \\
\hline $\begin{array}{l}\text { Household members (Ref. Two or } \\
\text { more) }\end{array}$ & & & & & & & & & & & & & & & \\
\hline One & 0.483 & $*$ & 0.235 & 0.384 & & 0.227 & 0.381 & & 0.224 & 0.318 & & 0.222 & 0.310 & & 0.233 \\
\hline $\begin{array}{l}\text { Education (Ref. Junior high school/ } \\
\text { high school) }\end{array}$ & & & & & & & & & & & & & & & \\
\hline $\begin{array}{l}\text { Junior (technical) college/ } \\
\text { vocational school }\end{array}$ & -0.010 & & 0.250 & 0.095 & & 0.241 & 0.036 & & 0.238 & 0.032 & & 0.236 & 0.283 & & 0.247 \\
\hline University/graduate school & -0.315 & & 0.230 & -0.309 & & 0.222 & -0.266 & & 0.219 & -0.227 & & 0.217 & -0.101 & & 0.228 \\
\hline $\begin{array}{l}\text { Household income (Ref. }<3 \text { million } \\
\text { yen) }\end{array}$ & & & & & & & & & & & & & & & \\
\hline 3-7 million yen & 0.219 & & 0.263 & 0.202 & & 0.254 & 0.158 & & 0.250 & 0.195 & & 0.248 & 0.110 & & 0.260 \\
\hline
\end{tabular}


Table 2 (continued)

\begin{tabular}{|c|c|c|c|c|c|c|c|c|c|c|c|c|c|c|c|}
\hline & \multicolumn{3}{|l|}{ Beg-Apr } & \multicolumn{3}{|l|}{ Mid-Apr } & \multicolumn{3}{|l|}{ End-Apr } & \multicolumn{3}{|l|}{ Beg-May } & \multicolumn{3}{|l|}{ Mid-May } \\
\hline & B & & S.E. & $\mathrm{B}$ & & S.E. & B & & S.E. & B & & S.E. & B & & S.E. \\
\hline 7 million yen or more & 0.319 & & 0.295 & 0.190 & & 0.285 & 0.118 & & 0.281 & 0.097 & & 0.279 & 0.085 & & 0.292 \\
\hline Unknown & 0.124 & & 0.327 & 0.032 & & 0.316 & 0.061 & & 0.311 & 0.026 & & 0.309 & -0.104 & & 0.324 \\
\hline \multicolumn{16}{|l|}{ Occupation (Ref. White-collar job) } \\
\hline Gray-collar job & -0.004 & & 0.237 & -0.051 & & 0.229 & -0.015 & & 0.225 & 0.169 & & 0.224 & 0.247 & & 0.234 \\
\hline Blue-collar job & 0.125 & & 0.326 & 0.150 & & 0.315 & 0.225 & & 0.311 & 0.179 & & 0.308 & 0.369 & & 0.323 \\
\hline Other & -0.551 & & 0.318 & -0.251 & & 0.307 & -0.353 & & 0.303 & -0.180 & & 0.301 & 0.361 & & 0.315 \\
\hline Not working & -1.078 & $* * *$ & 0.238 & -0.710 & $* *$ & 0.230 & -0.660 & $* *$ & 0.226 & -0.389 & & 0.225 & -0.456 & & 0.235 \\
\hline \multicolumn{16}{|l|}{ Use of public transportation (Ref. No) } \\
\hline Yes & -0.093 & & 0.188 & -0.271 & & 0.182 & -0.361 & * & 0.179 & -0.413 & * & 0.178 & -0.377 & * & 0.187 \\
\hline \multicolumn{16}{|l|}{ Chronic disease (Ref. No) } \\
\hline Yes & -0.036 & & 0.197 & -0.055 & & 0.190 & -0.128 & & 0.187 & -0.164 & & 0.186 & -0.221 & & 0.195 \\
\hline \multicolumn{16}{|l|}{ Large metropolitan areas (Ref. No) } \\
\hline Yes & -0.457 & $*$ & 0.212 & -0.460 & * & 0.232 & -0.293 & & 0.218 & -0.110 & & 0.217 & -0.422 & & 0.241 \\
\hline \multicolumn{16}{|l|}{$\begin{array}{l}\text { Neighborhood density (Ref. Lowest } \\
\text { (Non-DID)) }\end{array}$} \\
\hline $\begin{array}{l}\text { Low (DID with } 7,015 \text { people } / \mathrm{km}^{2} \\
\text { or fewer) }\end{array}$ & 0.019 & & 0.232 & 0.116 & & 0.224 & 0.156 & & 0.221 & 0.220 & & 0.220 & 0.471 & $*$ & 0.230 \\
\hline $\begin{array}{l}\text { High (DID with } 7,016-10,214 \\
\text { people } / \mathrm{km}^{2} \text { ) }\end{array}$ & 0.278 & & 0.247 & 0.139 & & 0.242 & 0.045 & & 0.237 & -0.079 & & 0.235 & -0.070 & & 0.248 \\
\hline $\begin{array}{l}\text { Highest (DID with } 10,215 \text { people/ } \\
\mathrm{km}^{2} \text { or more) }\end{array}$ & -0.172 & & 0.289 & -0.183 & & 0.290 & -0.152 & & 0.283 & -0.168 & & 0.281 & -0.086 & & 0.299 \\
\hline Constant & 4.678 & $* * *$ & 0.425 & 4.046 & $* * *$ & 0.411 & 3.722 & $* * *$ & 0.405 & 3.450 & $* * *$ & 0.402 & 3.791 & $* * *$ & 0.422 \\
\hline Prefecture-level variance & 0.000 & & 0.000 & 0.051 & & 0.069 & 0.029 & & 0.054 & 0.029 & & 0.052 & 0.061 & & 0.078 \\
\hline n (respondents) & 1163 & & & 1163 & & & 1163 & & & 1163 & & & 1163 & & \\
\hline $\mathrm{n}$ (prefectures) & 47 & & & 47 & & & 47 & & & 47 & & & 47 & & \\
\hline
\end{tabular}

$* * *: \mathrm{p}<0.001, * *: \mathrm{p}<0.01, * \mathrm{p}<0.05$

Table 3

Changes in the associations of time spent outside with anxiety variables estimated by a linear multilevel regression analysis, Japan, 2020.

\begin{tabular}{|c|c|c|c|c|c|c|c|c|c|c|c|c|c|c|c|}
\hline & \multicolumn{3}{|l|}{ Mid-Feb } & \multicolumn{3}{|l|}{ End-Feb } & \multicolumn{3}{|l|}{ Beg-Mar } & \multicolumn{3}{|l|}{ Mid-Mar } & \multicolumn{3}{|l|}{ End-Mar } \\
\hline & B & & S.E. & B & & S.E. & B & & S.E. & $\mathrm{B}$ & & S.E. & B & & S.E. \\
\hline \multicolumn{16}{|c|}{ Perceived risk of infection (Ref. No anxiety) } \\
\hline A little anxious & 0.111 & & 0.287 & -0.049 & & 0.307 & -0.168 & & 0.333 & -0.456 & & 0.341 & -0.570 & & 0.351 \\
\hline Somewhat anxious & -0.023 & & 0.292 & -0.049 & & 0.312 & 0.049 & & 0.339 & -0.213 & & 0.347 & -0.317 & & 0.357 \\
\hline Very anxious & -0.430 & & 0.308 & -0.444 & & 0.329 & -0.463 & & 0.357 & -1.066 & $* *$ & 0.365 & -1.093 & $* *$ & 0.377 \\
\hline \multicolumn{16}{|c|}{$\begin{array}{l}\text { Perceived stigma of going out (Ref. No } \\
\text { anxiety) }\end{array}$} \\
\hline A little anxious & -0.318 & & 0.193 & -0.234 & & 0.207 & -0.064 & & 0.224 & -0.128 & & 0.230 & -0.201 & & 0.236 \\
\hline Somewhat anxious & -0.171 & & 0.206 & -0.187 & & 0.220 & -0.091 & & 0.239 & -0.429 & & 0.244 & -0.410 & & 0.252 \\
\hline \multirow[t]{3}{*}{ Very anxious } & -0.160 & & 0.252 & -0.337 & & 0.270 & -0.273 & & 0.292 & -0.379 & & 0.299 & -0.363 & & 0.309 \\
\hline & \multicolumn{3}{|l|}{ Beg-Apr } & \multicolumn{3}{|l|}{ Mid-Apr } & \multicolumn{3}{|l|}{ End-Apr } & \multicolumn{3}{|l|}{ Beg-May } & \multicolumn{3}{|l|}{ Mid-May } \\
\hline & B & & S.E. & B & & S.E. & B & & S.E. & B & & S.E. & B & & S.E. \\
\hline \multicolumn{16}{|c|}{ Perceived risk of infection (Ref. No anxiety) } \\
\hline A little anxious & -0.444 & & 0.341 & -0.278 & & 0.328 & -0.187 & & 0.323 & -0.230 & & 0.321 & -0.160 & & 0.336 \\
\hline Somewhat anxious & -0.396 & & 0.346 & -0.343 & & 0.334 & -0.360 & & 0.329 & -0.418 & & 0.326 & -0.232 & & 0.342 \\
\hline Very anxious & -1.033 & $* *$ & 0.365 & -0.886 & * & 0.352 & -0.846 & * & 0.347 & -0.957 & ** & 0.344 & -0.948 & $* *$ & 0.361 \\
\hline \multicolumn{16}{|c|}{$\begin{array}{l}\text { Perceived stigma of going out (Ref. No } \\
\text { anxiety) }\end{array}$} \\
\hline A little anxious & -0.492 & * & 0.229 & -0.416 & & 0.221 & -0.362 & & 0.218 & -0.145 & & 0.216 & -0.261 & & 0.226 \\
\hline Somewhat anxious & -0.403 & & 0.244 & -0.466 & * & 0.235 & -0.484 & * & 0.232 & -0.307 & & 0.230 & -0.322 & & 0.241 \\
\hline Very anxious & -0.542 & & 0.299 & -0.686 & * & 0.288 & -0.708 & * & 0.284 & -0.639 & * & 0.282 & -0.556 & & 0.295 \\
\hline
\end{tabular}

Note: All independent variables in Table 2 were included in the regression models.

$* * *: \mathrm{p}<0.001, * *: \mathrm{p}<0.01, * \mathrm{p}<0.05$.

changes.

Additionally, the two anxiety variables, perceived risk of infection and perceived stigma of going out, were also statistically significantly related to time spent outside. This may support the theoretical model proposed by Katafuchi et al. (2020), which suggests that those who leave their homes may experience psychological costs arising from the stigma of going out and the perceived risk of infection. Particularly, the periods in which the perception of stigma was significantly associated with going-out behavior overlapped with when the state of emergency had been declared. This may indicate that people began to feel anxious about stigma when they went out during the state of emergency, even though it was a request for self-restraint and not legally enforceable.

This study has several limitations. First, respondents were recruited from registered panel members of a survey company and did not represent a random sample of the Japanese population, limiting the external validity of the findings. Second, the results were based on retrospective, self-reported, and relative evaluations of time spent outside, which could introduce a recall bias, although we included characteristic events in each period in the questionnaire to reduce any potential bias. Further analysis using more objective data should be 
conducted. Third, the two anxiety variables were assessed at the time of the survey and were not retrospectively evaluated. A repeated longitudinal survey is needed to determine the causal effect. Finally, the findings of this study are time-and country-specific, as the situation regarding COVID-19 has been rapidly changing and differs by country and region.

\section{Conclusion}

It is important to have access to basic information regarding who is staying home and who is not, to permit effective COVID-19 research and policy formulation. Using an online survey in Japan, this study investigated respondents' retrospective perception of time spent outside, before and after a state of emergency was declared. Overall, respondents generally tended to reduce their going-out time during the study period, despite the non-mandatory lockdown policy. However, respondents who were young, female, lived with two or more household members, had lower incomes, were not working, used public transportation, had chronic diseases, and lived in large metropolitan areas were more likely to stay home during a part of the study period. Although not salient in this study, socioeconomic and geographic differences in going-out behavior and their influence on health should be continuously monitored.

\section{CRediT authorship contribution statement}

Tomoya Hanibuchi: Conceptualization, Methodology, Funding acquisition, Formal analysis, Writing - original draft. Naoto Yabe: Methodology, Writing - review \& editing. Tomoki Nakaya: Conceptualization, Supervision, Writing - review \& editing.

\section{Declaration of Competing Interest}

The authors declare that they have no known competing financial interests or personal relationships that could have appeared to influence the work reported in this paper.

\section{Acknowledgements}

This work was supported by JSPS KAKENHI, Japan (Grant Numbers JP17H00947, JP18KK0371, and JP20H00040) and Starting Grants for Research toward Resilient Society (Tohoku University).

\section{References}

Amram, O., Amiri, S., Lutz, R.B., Rajan, B., Monsivais, P., 2020. Development of a vulnerability index for diagnosis with the novel coronavirus, COVID-19, in Washington State, USA. Health Place 64, 102377. https://doi.org/10.1016/j. healthplace:2020.102377.

Baena-Díez, J. M., Barroso, M., Cordeiro-Coelho, S. I., Díaz, J. L., Grau, M., 2020. Impact of COVID-19 outbreak by income: Hitting hardest the most deprived. J. Public. Health. fdaa136. DOI:10.1093/pubmed/fdaa136.
Bambra, C., Riordan, R., Ford, J., Matthews, F., 2020. The COVID-19 pandemic and health inequalities. J. Epidemiol. Community Health.

Goethals, L., Barth, N., Guyot, J., Hupin, D., Celarier, T., Bongue, B., 2020. Impact of home quarantine on physical activity among older adults living at home during the COVID-19 pandemic: qualitative interview study. JMIR Aging 3 (1), e19007. https:// doi.org/10.2196/19007.

Hamidi, S., Ewing, R., Sabouri, S., 2020. Longitudinal analyses of the relationship between development density and the COVID-19 morbidity and mortality rates: Early evidence from 1,165 metropolitan counties in the United States. Health. Place. 64, 102378. DOI:10.1016\%2Fj.healthplace.2020.102378.

Islam, N., Sharp, S. J., Chowell, G., Shabnam, S., Kawachi, I., Lacey, B., et al., 2020. Physical distancing interventions and incidence of coronavirus disease 2019: Natural experiment in 149 countries. BMJ. 370, m2743. DOI:10.1136/bmj.m2743.

Japanese Ministry of Health, Labour and Welfare 2020a. About coronavirus disease 2019 (COVID-19). https://www.mhlw.go.jp/stf/seisakunitsuite/bunya/newpage_00032. html (accessed 8 September 2020).

Japanese Ministry of Health, Labour and Welfare 2020b. Accumulated total of confirmed cases by prefectures. https://www.mhlw.go.jp/content/10900000/000668285.pdf (accessed 8 September 2020).

Johns Hopkins Coronavirus Resource Center 2020. COVID-19 dashboard. https://cor onavirus.jhu.edu/map.html (accessed 8 September 2020).

Katafuchi, Y., Kurita, K., Managi, S., 2020. COVID-19 with stigma: Theory and evidence from mobility data. Econ. Dis. Cli. Cha. DOI:10.1007/s41885-020-00077-w.

Khalatbari-Soltani, S., Cumming, R.C., Delpierre, C., Kelly-Irving, M., 2020. Importance of collecting data on socioeconomic determinants from the early stage of the COVID19 outbreak onwards. J. Epidemiol. Community. Health. 74 (8), 620-623. https:// doi.org/10.1136/jech-2020-214297.

Killgore, W. D. S., Cloonan, S. A., Taylor, E. C., Dailey, N. S., 2020. Loneliness: A signature mental health concern in the era of COVID-19. Psychiatry. Res. 290, 113117. DOI:10.1016\%2Fj.psychres.2020.113117.

Machida, M., Nakamura, I., Saito, R., Nakaya, T., Hanibuchi, T., Takamiya, T., et al., 2020. Changes in implementation of personal protective measures by ordinary Japanese citizens: a longitudinal study from the early phase to the community transmission phase of the COVID-19 outbreak. Int. J. Infect. Dis. 96, 371-375. https://doi.org/10.1016/j.ijid.2020.05.039.

Muto, K., Yamamoto, I., Nagasu, M., Tanaka, M., Wada, K., 2020. Japanese citizens' behavioral changes and preparedness against COVID-19: An online survey during the early phase of the pandemic. Plos One. 15 (6), e0234292 https://doi.org/10.1371/ journal.pone.0234292.

Oronce, C.I.A., Scannell, C.A., Kawachi, I., Tsugawa, Y., 2020. Association between statelevel income inequality and COVID-19 cases and mortality in the USA. J. Gen. Intern. Med. 35 (9), 2791-2793. https://doi.org/10.1007/s11606-020-05971-3.

Parady, G., Taniguchi, A., Takami, K., 2020. Travel behavior changes during the COVID19 pandemic in Japan: analyzing the effects of risk perception and social influence on going-out self-restriction. Transp. Res. Interdiscip. Perspect. 7, 100181. https:// doi.org/10.1016/j.trip.2020.100181.

Power, K., 2020. The COVID-19 pandemic has increased the care burden of women and families. Sustainability: Sci. Pract. Policy 16 (1), 67-73. https://doi.org/10.1080/ 15487733.2020.1776561.

Tison, G.H., Avram, R., Kuhar, P., Abreau, S., Marcus, G.M., Pletcher, M.J., Olgin, J.E., 2020. Worldwide effect of COVID-19 on physical activity: a descriptive study. Ann. Intern. Med. 173 (9), 767-770. https://doi.org/10.7326/M20-2665.

Tull, M. T., Edmonds, K. A., Scamaldo, K. M., Richmond, J. R., Rose, J. P., Gratz, K. L., 2020. Psychological outcomes associated with stay-at-home orders and the perceived impact of COVID-19 on daily life. Psychiatry Res. 289, 113098. DOI: 10.1016\%2Fj.psychres.2020.113098.

Yabe, T., Tsubouchi, K., Fujiwara, N., Wada, T., Sekimoto, Y., Ukkusuri, S. V., 2020. NonCompulsory measures sufficiently reduced human mobility in Japan during the COVID-19 epidemic. arXiv:2005.09423.

Yamamura, E., Tsutsui, Y., 2020. Impact of the state of emergency declaration for COVID-19 on preventive behaviors and mental conditions in Japan: Difference in difference analysis using panel data. Papers 2005.13008, arXiv.org.

Zhang, C.H., Schwartz, G.G., 2020. Spatial disparities in coronavirus incidence and mortality in the United States: an ecological analysis as of May 2020. J. Rural. Health 36 (3), 433-445. https://doi.org/10.1111/jrh.12476. 